\title{
Espécies novas de Ischnoptera (Blattellidae, Blattellinae) do Estado do Mato Grosso, Brasil e considerações sobre I. similis
}

\author{
Sonia Maria Lopes
}

Departamento de Entomologia, Museu Nacional, Universidade Federal do Rio de Janeiro, Quinta da Boa Vista, São Cristóvão, 20940-040 Rio de Janeiro, RJ, Brasil. Pesquisadora de Produtividade Científica do CNPq. (sonialfraga@gmail.com)

\begin{abstract}
New species of Ischnoptera (Blattellidae, Blattellinae) from Mato Grosso State, Brazil and considerations about I. similis. Three new species of Ischnoptera Burmeister, 1838 from Mato Grosso State, Brazil are described (I. miuda, I. irregulata, I. pantaneira). Illustrations of male and female genitalia are presented. Ischnoptera cristata nom. nov. for I. similis Rocha e Silva, 1984, not I. similis R. S.-Albuquerque \& Lopes, 1977.
\end{abstract}

KEYWORDS. Blattaria, Ischnoptera, new species, Neotropical, Taxonomy.

RESUMO. Três espécies novas de Ischnoptera Burmeister, 1838 do Estado do Mato Grosso, Brasil são descritas (I. miuda, I. irregulata, I. pantaneira). Ilustrações da genitália do macho e fêmea são apresentadas. Ischnoptera cristata nom. nov. para I. similis Rocha e Silva, 1984, non I. similis R. S.-Albuquerque \& Lopes, 1977.

PALAVRAS-CHAVE. Blattaria, Ischnoptera, espécies novas, Neotropical, Taxonomia.

Ischnoptera foi descrito por BURMEISTER (1838) com base em Ischnoptera morio, designada por KIRBY (1904) como espécie-tipo. Caracterizam-se por possuírem tégminas ultrapassando em comprimento o ápice dos cercos; campo marginal estreito e defletido; campo escapular oblíquo e alongado; campo discoidal longitudinal e campo anal amplo com sete ou mais veias; asas desenvolvidas, triângulo apical pouco desenvolvido e campo anal dobrado em leque; pernas alongadas e espinhosas, fêmur anterior com espinhos robustos e espaçados, da base até à região mediana, sucedidos por uma série cerrada de espinhos diminutos até o ápice e dois a três apicais robustos; face póstero-ventral com espinhos robustos espaçados; fêmures médio e posterior com espinhos robustos e espaçados nas faces ântero- e pósteroventrais e espinho genicular; tarsos com pulvilos em todos os artículos e com arólios pouco desenvolvidos; unhas simétricas e simples.

Ischnoptera foi rediagnosticado por Rотн (2001) com base em sete espécies reunidas no grupo darlingtoni, pela configuração da placa supra-anal do macho e o ápice do esclerito mediano.

Os espécimes de Ischnoptera estão distribuídos na Região Neotropical, e para o Brasil estão assinaladas 45 espécies, das quais apenas seis para a região CentroOeste: I. brunnea R. S.-Albuquerque, 1964, I. brasiliana Rocha e Silva, 1984, I. neomelasa Rocha e Silva, 1984, I. similis Rocha e Silva, 1984, I. bicolorata Lopes \& Oliveira, 2005, I. rugosa Lopes \& Oliveira, 2006.

São feitas considerações sobre $I$. similis e ilustradas as genitálias de macho e fêmeas das três espécies novas.

\section{MATERIAL E MÉTODOS}

Os exemplares foram coletados em Sinop, no Estado de Mato Grosso, Brasil, localizada a 500 quilômetros ao norte de Cuiabá, às margens da BR-163, a CuiabáSantarém, em uma altitude de $345 \mathrm{~m}$.
A observação das placas genitais seguiu Lopes \& Oliveira (2000) e a designação das peças genitais e a classificação taxonômica foram baseadas nos conceitos propostos por Rотн (2003).

Após análise, as placas e peças genitais foram guardadas em microtubos contendo glicerina e devidamente acondicionados junto ao exemplar respectivo montado em alfinete entomológico, na coleção entomológica do Museu Nacional, Rio de Janeiro.

\section{Ischnoptera cristata nom. nov.}

Ischnoptera similis Rocha E Silva, 1984:211, figs. 24, 25 non $I$. similis R. S.-Albuquerque \& Lopes, 1977:513, figs. 49-51.

Rocha e Silva-Albuquerque \& Lopes (1977) descreveram I. similis como pertencente ao "grupo flagillifer Hebard e próxima a I. inusitata (R. S.Albuquerque)" com base na configuração das placas supra-anal e subgenital.

Rocha e SiLva (1984) descreveu uma nova espécie de Ischnoptera "pertencente ao grupo rufa", a qual indevidamente denominou também como I. similis.

BECCALONI (2007) em seu catálogo considerou a $I$. similis descrita em 1984 como um homônimo primário.

Propõe-se I. cristata nom. nov., devido à configuração do ápice do esclerito mediano em forma de crista, como pode ser visto em Rocha E Silva, 1984:211 figs. 24, 25, permanecendo como $I$. similis aquela descrita em Rocha e Silva-Albuquerque \& Lopes (1977).

\section{Ischnoptera miuda sp. nov.} (Figs. 1-8)

Descrição. Coloração geral castanho brilhante. Cabeça com fronte e manchas mais escuras, dispersas na fronte, próximo à inserção das antenas, na base dos olhos, clareando em direção ao clípeo (Fig. 1), antenas bicoloridas 
com a metade basal escura, metade apical castanho amarelada e os dois últimos artículos apicais escuros; palpos maxilares amarelados com a extremidade do artículo apical castanho-escura. Pernas castanhas com tíbias amareladas. Abdome no sétimo segmento com faixa e mancha elipsóide simétrica castanho-escuras (Fig. 2).

Cabeça triangular com vértice exposto, espaço interocular estreito medindo metade da área que separa as bases das inserções antenais; fronte projetada e saliente, ocelos desenvolvidos e defletidos; antenas filiformes, longas e tomentosas.

Tórax com pronoto no ápice e base retos e abas laterais com entorno arredondado; disco central com sulcos divergentes bem marcados.

Abdome apresentando o sétimo tergito medianamente com duas projeções divergentes em forma de pente com cinco espinhos dispostos na margem interna
(Fig. 2). Placa supra-anal com projeção, entre os cercos, arredondada e com cerdas nas bordas, parapróctos esclerotinizados; cercos alongados (Fig. 3). Placa subgenital assimétrica e com cerdas; na região central ocorre uma reentrância mediana onde apicalmente se inserem cada um dos estilos, levemente diferenciados em tamanho, com espinhos nas bordas (Fig. 4). Falômero esquerdo em forma de gancho apicalmente dilatado (Fig. 5). Esclerito mediano com haste afilada e ápice acuminado (Fig. 6).

Medidas em mm, ơ (holótipo). Comprimento total, 11,0; comprimento do pronoto, 2,0; largura do pronoto, 3,0; comprimento da tégmina, 9,0; largura da tégmina, 3,0.

A fêmea apresenta placa supra-anal acuminada entre os cercos, os quais são curtos, roliços e ciliados (Fig. 7). Complexo valvular apresentando pares de válvulas diferenciados, sendo o terceiro par menor que os demais. Valvíferos diferenciados (Fig. 8).
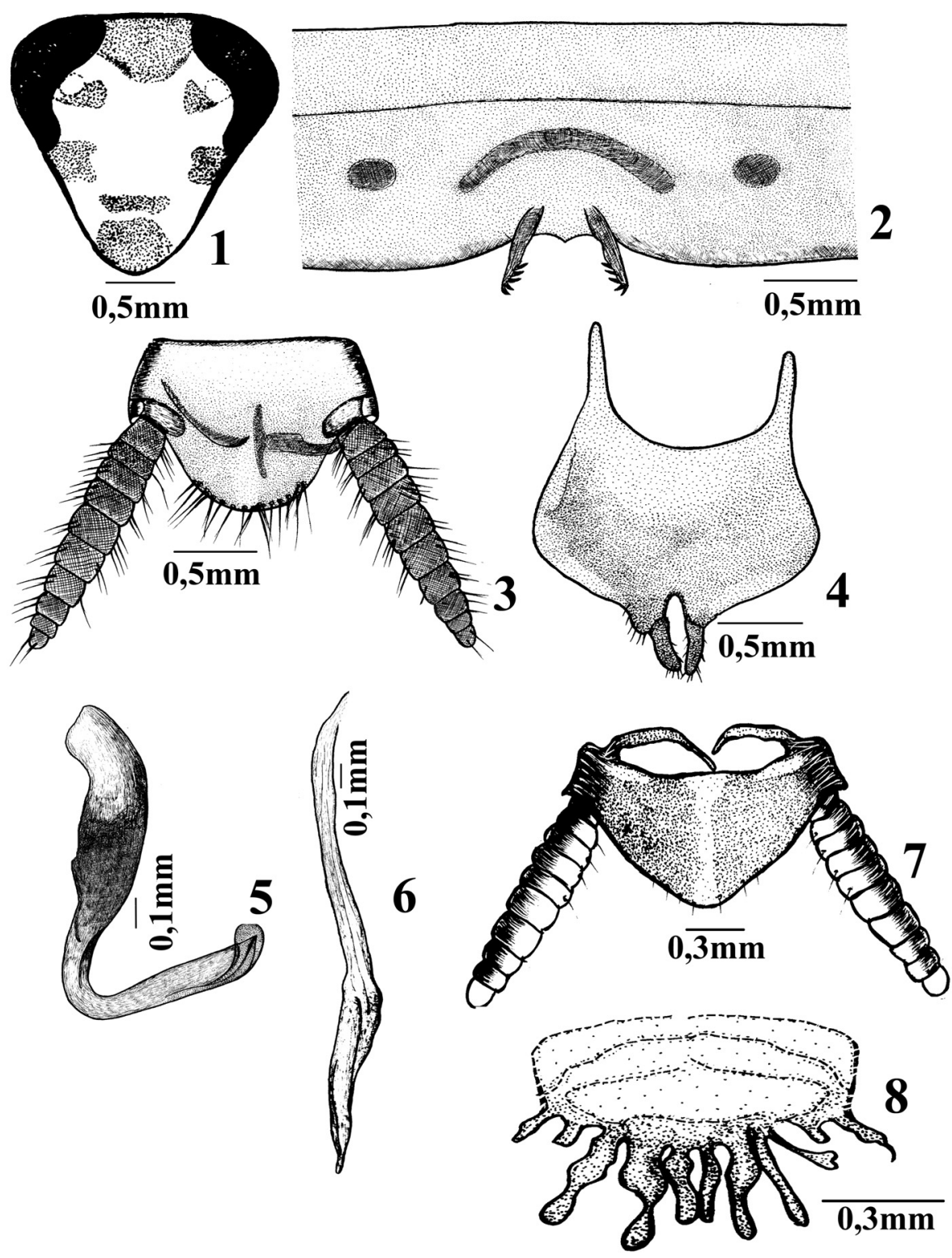

Figuras 1-8. Ischnoptera miuda sp. nov. Holótipo ơ: 1, cabeça, ventral; 2, modificação do sétimo tergito, dorsal; 3, placa supra-anal, dorsal; 4, placa subgenital, ventral; 5, falômero esquerdo, dorsal; 6, esclerito mediano, dorsal; parátipo 9 : 7, placa supra-anal, dorsal; 8 , complexo de válvulas, dorsal. 
Medidas em mm, ․ Comprimento total, 11,0; comprimento do pronoto, 2,0; largura do pronoto, 3,0; comprimento da tégmina, 9,0; largura da tégmina, 3,0.

Material-tipo. Holótipo ơ, BRASIL, Mato Grosso: Sinop, $12^{\circ} 31^{\prime} \mathrm{S}, 55^{\circ} 37^{\prime} \mathrm{W}, \mathrm{BR} 163$, Km 500 a $600,350 \mathrm{~m}$ alt., IX/1974, Alvarenga \& Roppa col.; 4 parátipos $\sigma^{7}$ e 1 parátipo $\odot$, dados iguais ao holótipo.

Etimologia. O nome da espécie deve-se ao tamanho.

Diagnose. I. miuda sp. nov. é distinta entre as demais espécies do gênero pela configuração da placa subgenital que apresenta reentrância mediana onde apicalmente se inserem cada um dos estilos.

\section{Ischnoptera irregulata sp. nov.}

(Figs. 9-16)

Descrição. Coloração geral castanho, brilhante. Cabeça castanho-escura, com manchas mais claras dispersas (Fig. 9); palpos maxilares, labiais e antenas castanhos. Tégminas com campo marginal hialino. Pernas castanhas, com região basal da coxa e dorsal do fêmur mais escuras.

Cabeça alongada, subtriangular, vértice pouco exposto em vista dorsal, espaço interocular regular, medindo cerca da metade da área que separa as bases das inserções antenais; fronte saliente com ocelos evidenciados e defletidos; palpos maxilares e labiais desenvolvidos; palpos maxilares com terceiro artículo longo, o quarto e quinto artículos dilatados e muito tomentosos; antenas longas, filiformes e tomentosas.

Tórax com pronoto subtrapezoidal, abas laterais amplas e defletidas; disco central apresentando dois sulcos divergentes em direção ao ápice.

Abdome apresentando modificação tergal semelhante à $I$. miuda $\mathrm{sp}$. nov. Placa supra-anal projetada entre os cercos com formato irregular e com reentrância acentuada látero-medianamente. Cercos alongados e ciliados (Fig. 10). Placa subgenital assimétrica, com cerdas; estilos na região central médioapical, pequenos, forma e tamanho diferenciados entre si, bem afastados um do outro e sem espinhos (Fig. 11). Falômero esquerdo em forma de gancho, apicalmente muito dilatado e com reentrância pré-apical acentuada (Fig. 12). Esclerito mediano afilado com ápice alargado espinhoso (Fig. 13). Falômero direito sem forma definida (Fig. 14).

Medidas em mm, ơ (holótipo). Comprimento total, 19,0; comprimento do pronoto, 3,5; largura do pronoto, 5,0 ; comprimento da tégmina, 16,0 ; largura da tégmina, 4,0 .

A fêmea difere do macho por apresentar placa supraanal, entre os cercos, acuminada apicalmente. Cercos curtos, roliços e ciliados (Fig. 15); complexo valvular com os pares de válvulas diferenciados sendo o terceiro par menor que todos os demais (Fig. 16).

Medidas em mm,, (média). Comprimento total, 11,0; comprimento do pronoto, 2,0; largura do pronoto, 3,0; comprimento da tégmina, 9,0; largura da tégmina, 3,0 .
Material-tipo. Holótipo o ${ }^{7}$, BRASIL, Mato Grosso: Sinop, $12^{\circ} 31^{\prime} \mathrm{S}, 55^{\circ} 37^{\prime} \mathrm{W}, \mathrm{BR} 163, \mathrm{~km} 500-600,350 \mathrm{~m}$ alt., X/1974, Alvarenga \& Roppa col.; 5 parátipos $0^{7}$ e 4 parátipos + , dados iguais ao holótipo.

Etimologia. O nome da espécie foi dado com base na configuração irregular da placa supra-anal do macho.

Diagnose. I. irregulata sp. nov. pela configuração da placa subgenital e pelo espaçamento dos estilos, assemelha-se a I. campana Albuquerque \& Fraga, 1976, dela diferindo e de todas as demais espécies do gênero pela configuração do esclerito mediano afilado.

\section{Ischnoptera pantaneira sp. nov.} (Figs. 17-23)

Descrição. Coloração geral castanho-escura brilhante. Cabeça com olhos negros, ocelos bem marcados, manchas escuras dispersas na face (Fig. 17); antenas, palpos maxilares e labiais castanhos, com tomentosidade dourada. Tégminas castanhas, campo marginal e parte basal do campo escapular mais claros; pernas com fêmures, tíbias e tarsos com tomentosidade dourada.

Cabeça pequena com entorno apical arredondado; vértice levemente exposto sob o pronoto, em vista dorsal; espaço interocular medindo cerca da metade da área que separa as bases das inserções antenais; ocelos desenvolvidos, bem marcados e defletidos em relação à fronte, esta projetada e saliente; antenas e palpos maxilares e labiais desenvolvidos.

Tórax com pronoto subtriangular, com ápice e base retos, entorno lateral arredondado e defletido; disco central com dois sulcos divergentes bem marcados.

Abdome apresentando modificação tergal semelhante à I. irregulata sp. nov. (Fig. 18). Placa supraanal projetada entre os cercos com cerdas nas bordas; parapróctos evidenciados e esclerotinizados; cercos alongados (Fig. 19). Placa subgenital assimétrica e com cerdas; estilos curtos com espinhos, diferenciados em forma e tamanho, e localizados na região central médioapical em uma saliência da placa (Fig. 20). Falômero esquerdo em forma de gancho apicalmente dilatado e com reentrância pré-apical acentuada (Fig. 21). Esclerito mediano com haste recurvada, ápice afilado, com pequenos espinhos na borda da região mediana à préapical (Fig. 22).

Medidas em mm, ơ (holótipo). Comprimento total, 24,0; comprimento do pronoto, 5,0; largura do pronoto, 6,0 ; comprimento da tégmina, 20,0; largura da tégmina, 5,0 .

A fêmea difere do macho por apresentar placa supraanal pronunciada e acuminada entre os cercos, os quais se apresentam curtos, roliços e ciliados (Fig. 23). Complexo valvular apresentando os pares de válvulas diferenciados sendo os segundo e terceiro pares semelhantes em comprimento. Valvíferos diferenciados.

Medidas em mm, : Comprimento total, 23,0; comprimento do pronoto, 4,5 ; largura do pronoto, 6,0 ; comprimento da tégmina, 20,0; largura da tégmina, 5,0. 


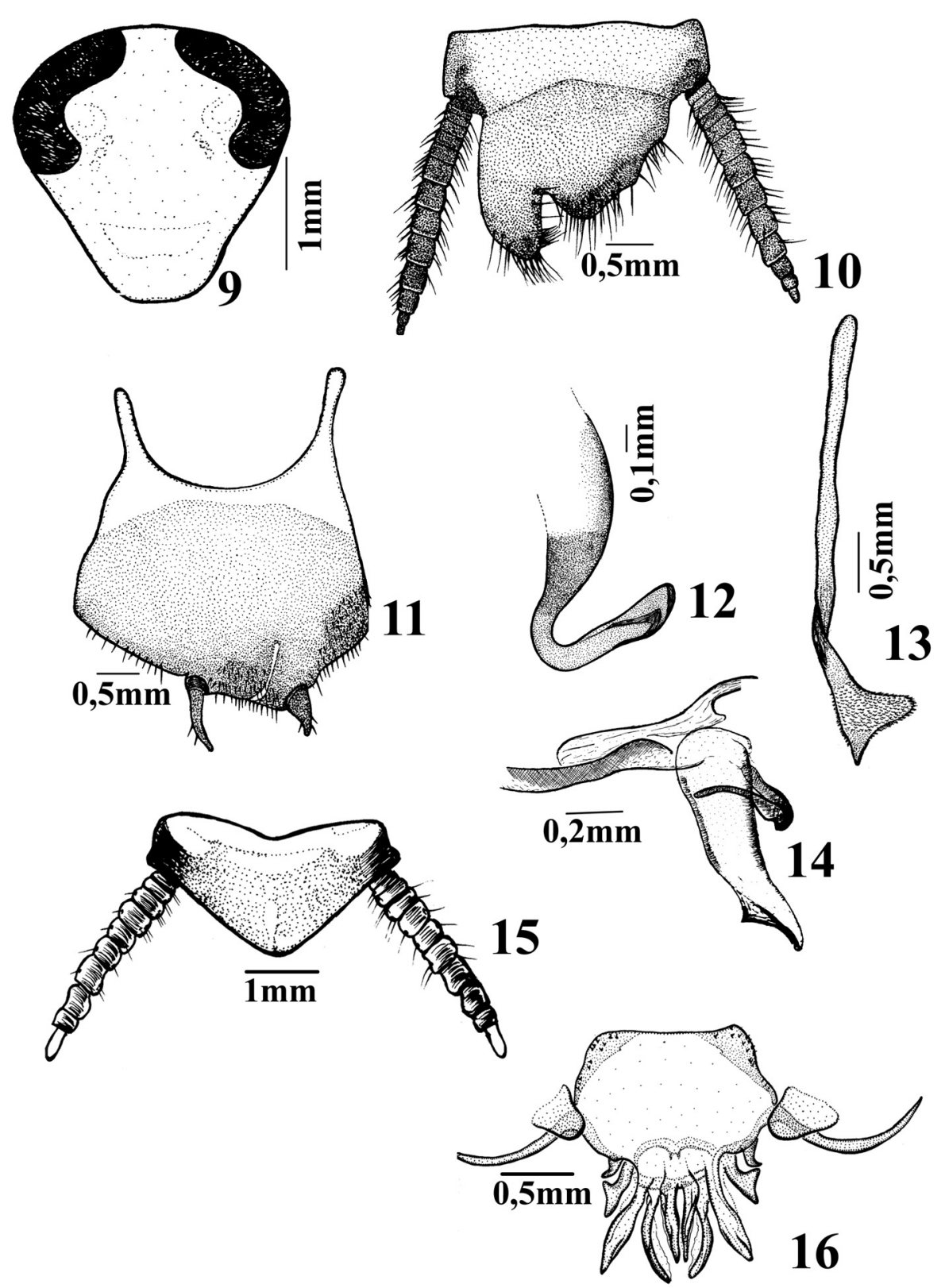

Figuras 9-16. Ischnoptera irregulata sp. nov. Holótipo ơ: 9, cabeça, ventral; 10, placa supra-anal, dorsal; 11, placa subgenital, ventral; 12, falômero esquerdo, dorsal; 13, esclerito mediano, dorsal; parátipo i: 14, falômero direito, dorsal; 15, placa supra-anal, dorsal; 16 , complexo de válvulas.

Material-tipo. Holótipo ơ, BRASIL, Mato Grosso: Sinop, $12^{\circ} 31^{\prime} \mathrm{S}, 55^{\circ} 37^{\prime} \mathrm{W}, \mathrm{BR} 163, \mathrm{~km} 500-600,350 \mathrm{~m}$ alt., X/1974, Alvarenga \& Roppa col.; 1 parátipo $\sigma^{7}$ e 1 parátipo + , dados iguais ao holótipo.

Etimologia. O nome da espécie é alusivo à região onde se localiza o município onde foi coletada.

Diagnose. I. pantaneira sp. nov. pela configuração da placa subgenital assemelha-se à I. rufa De Geer, 1773, diferindo pela configuração do esclerito mediano, cujo ápice não é afilado apicalmente.

\section{DISCUSSÃO}

A inclusão das espécies propostas em Ischnoptera justifica-se por possuírem modificação tergal no abdome no sétimo e oitavo segmentos (Roth apud ATKInson et $a l ., 1992$ ), o fêmur anterior com quatro a cinco espinhos robustos e espaçados, da base até a região mediana, sucedidos por uma série cerrada de espinhos diminutos até o ápice com espinhos apicais em número de três ( $I$. cristata, I. irregulata, I. pantaneira) ou dois (I. miuda); no abdome a placa supra-anal do macho projetada, com reentrância mediana acentuada entre os cercos $(I$. irregulata) ou não (I. cristata, I. miuda, I. pantaneira) e a placa subgenital assimétrica, com estilos diferenciados entre eles localizados em protuberâncias da placa na região central do ápice da mesma (I. cristata, I. pantaneira) ou não (I. miuda, I. irregulata). 

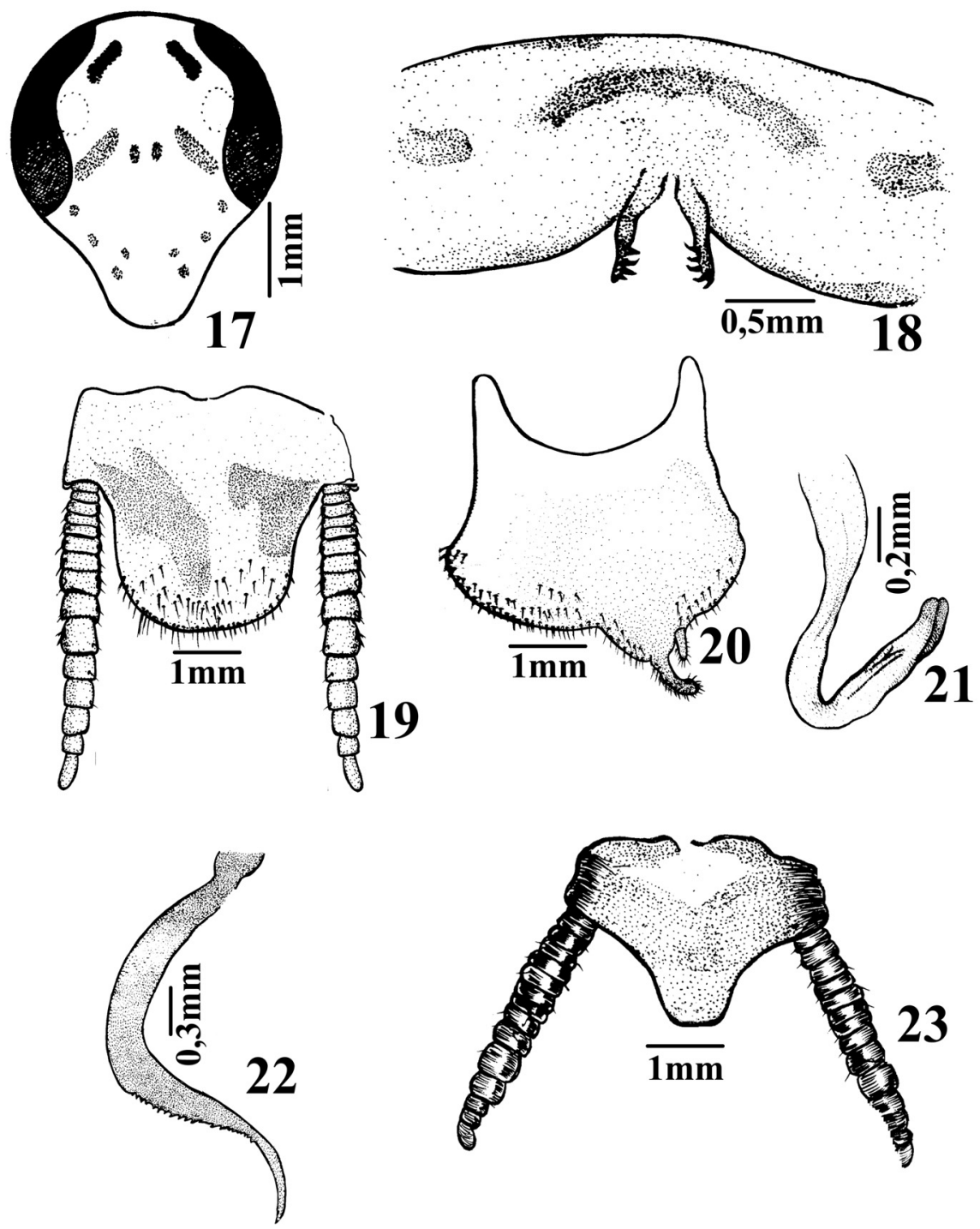

Figuras 17-23. Ischnoptera pantaneira sp. nov. Holótipo ơ: 17, cabeça, ventral; 18, modificação do sétimo tergito, dorsal; 19, placa supra-anal, dorsal; 20, placa subgenital, ventral; 21, falômero esquerdo, dorsal; 22, esclerito mediano, dorsal; parátipo o: 23, placa supra-anal, dorsal.

\section{REFERÊNCIAS BIBLIOGRÁFICAS}

Atkinson, T. H.; Mangold, J. R. \& Koehler, P. G. 1992. Two neotropical cockroaches of the genus Ischnoptera (Dictyoptera: Blattellidae) established in Florida. Florida Entomologist 75(1):109-115.

Beccaloni, G. W. 2007. Blattodea Species File Online. Version 1.2/3.1. World Wide Web electronic publication. Disponível em: <http://Blattodea.SpeciesFile.org>. Acesso em: 15.10.2007.

Burmeister, H. 1838. Blattina. In: Handbuch der Entomologie. Berlin, I.C.F. Enslin 2(2):469-517.

KirBy, W. F.1904. A synonymic catalogue of Orthoptera Euplexoptera, Cursoria et Goessinia (Forficulidae, Hemimeridae, Blattidae, Mantidae, Phasmidae). London, British Museum. v.1, 501p.

Lopes, S. M. \& Oliveira, E. H. 2000. Espécie nova de Eublaberus
Hebard, 1919 do Estado de Goiás, Brasil e notas sobre E. marajoara Rocha e Silva-Albuquerque, 1972 (Blaberidae, Blaberinae). Boletim do Museu Nacional, Nova Série, Zoologia, 433:1-5.

Rocha E Silva, I. 1984. Blattaria da Amazônia - Sobre alguns Blattellidae de Sinop, Mato Grosso, Brasil (Dictyoptera, Blattodea). Revista Brasileira de Entomologia 28(3):207-212. Rocha e Silva-Albuquerque, I. \& Lopes, S. M. 1977. Blattaria (Dictyoptera) do Alto da Mosela, Petrópolis, RJ. Revista Brasileira de Biologia 37(3):499-520.

Rотн, L. M. 2001. The genus Ischnoptera Burmeister. I. The darlingtoni-species-group, with seven new species (Blattaria: Blattellidae, Blattellinae). Transactions of the American Entomological Society 127(4):519-541.

2003. Systematics and phylogeny of cockroaches (Dictyoptera: Blattaria). Oriental Insects 37:1-186. 